\title{
Evaluating the activity of dispensing opioid analgesic medication
}

\author{
Elena DINTE ${ }^{1}$, Radu BORZA ${ }^{1}$, Oana MOCAN GURKA ${ }^{1}$ \\ ${ }^{1}$ Department of Pharmaceutical Technology and Biopharmaceutics, Faculty of Pharmacy, "Iuliu Hatieganu" \\ University of Medicine and Pharmacy, Cluj-Napoca, Romania
}

\begin{abstract}
Objectives. The purpose of this paper was to evaluate the drug dispensing activity of analgesic opioids in pharmacies.

Materials and methods. The study was conducted in an observational and retrospective manner, based on a questionnaire distributed in different pharmacies across Romania.

Results. The dispensing activity of opioid analgesics is conducted in 71 out of the 100 pharmacies that have received the questionnaire. These pharmacies are located in 12 out of the 41 counties, mostly in the urban area and $96 \%$ of them are community pharmacies. The most prescribed and dispensed pharmaceutical forms are solid forms, the injectable products and transdermic systems being dispensed in a high percentage, up to $40 \%$ respectively, only in $25 \%$ of the questioned pharmacies. The average time spent by a pharmacist for the entire activity of dispensing an opioid analgesic prescribed by a doctor was estimated at $17.82 \pm 0.58$ minutes.

Conclusions. The activity regarding opioid analgesics in the community pharmacy is limited by the low rentability, high costs and time consumption. The results of the study impose a further analysis on the impact that this service has upon public health, in order to this activity be sustained by the national health insurance system. Measures must be implemented to ensure that patients from rural or unprivileged areas are able to get their analgesics from the nearest community pharmacy constantly.
\end{abstract}

Keywords: opioids, cancer pain, community pharmacy, pharmaceutical service

\section{INTRODUCTION}

Self-medication, according to the dictionary definition, Pain is the most frequent symptom that the patients claim when going to see a doctor. It is the main symptom for $50 \%$ of the patients diagnosed with cancer, especially in the advanced forms (1-4).

Regarding oncology patients, pain and discomfort represent a form of suffering which imposes the use of analgezics, more specifically opioids (5-8).

Opioid analgesics are under high scrutiny $(9,10,11)$. The legal provisions which regulate the activities regarding this type of medication can be found in the Law No 339/2015 (9). Prescribing this type of medication can only be done on special and secured documents, in hospitals. The validity of the prescription is 10 days from the issuing date and can contain up to 3 separate products, even if the active substance is the same between them, but comes in different pharmaceutical forms. The prescription can only include the medication necessary for 30 days. The physician is allowed to hand out a new prescription for the same patient before the 30 days have expired if during the treatment the patient's 
TABLE 1. The number of responding pharmacies based on type and placement

\begin{tabular}{|c|c|c|c|c|}
\hline $\begin{array}{c}\text { Type of } \\
\text { pharmacy }\end{array}$ & \multicolumn{2}{|c|}{ Hospital } & \multicolumn{2}{c|}{ Community } \\
\hline Placement & Rural & Urban & Rural & Urban \\
\hline $\begin{array}{c}\text { Number of } \\
\text { pharmacies }\end{array}$ & 0 & 4 & 15 & 81 \\
\hline
\end{tabular}

health status alterate to a degree that imposes changes in dose or type of medication, or if the prescribed dose has been used up.

All the opioid analgesics which have been obtained through a medical prescription and have remained unused at the end of the treatment must be returned to the pharmacy which dispensed them to the patient. This process must be recorded on a signed statement. All the medications must be recorded daily in a special registry by a designated person in each and every pharmacy (10-11).

\section{OBJECTIVE}

The purpose of this paper was to evaluate the pharmacists' activity of dispensing opioid analgesics to patients through a medical prescription issued by a physician. Furthermore, this paper served for this identification of practical problems which pharmacists have to handle through this process.

\section{MATERIALS AND METHODS}

The study had been conducted by observation, in a retrospective manner. It was based on a questionnaire which was distributed in different pharmacies, both community and hospital, from Romania. The questionnaire was completed by the head pharmacist and the results have been analyzed comparatively and are stated numerically and in percentages.

\section{RESULTS AND DISCUSSION}

100 pharmacists have responded to this questionnaire, 85 of them from urban area and the other 15 from rural area. Out of the 100 pharmacies questioned, 4 are hospital pharmacies located in the urban area and the other 96 are community pharmacies, of which 81 are located in urban areas (Table 1).

Next, we will approach and discuss about the community pharmacies, since the number of hospital pharmacies is too low to be statistically relevant. Out of the total 96 pharmacies, 77 are independent and the other 19 are part of a pharmacy chain (data not shown).

Regarding geographical distribution of the responding pharmacies, the questionnaire has reached 12 out of 41 counties. The most responses came from Cluj (56\%), Mureş (10\%), Maramures (8\%), Salaj (7\%),

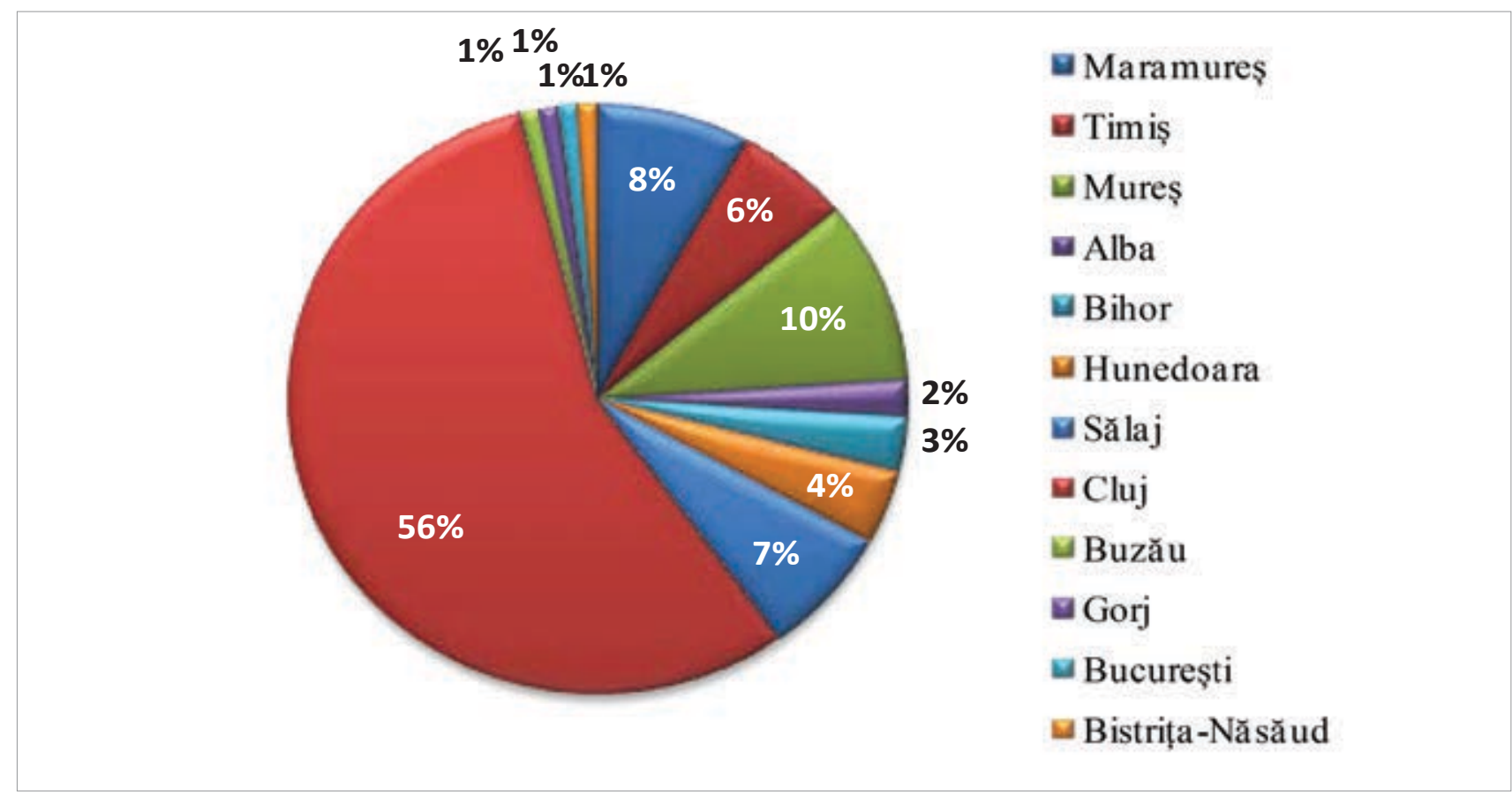


Timiş (6\%), followed by another 7 with smaller percentages (Fig. 1).

The majority of responding pharmacists have between 1 and 10 years of experience in this profession (48.4\%); $23.6 \%$ have been in this profession for more than 30 years and $22.6 \%$ have $10-20$ years of experience as a community pharmacist (Table 2).

TABLE 2. Professional experience (years) of responding pharmacists (\%)

\begin{tabular}{|c|l|l|l|l|}
\hline $\begin{array}{c}\text { Professional } \\
\text { experience } \\
\text { (years) }\end{array}$ & $<\mathbf{1 0}$ & $\mathbf{1 0 - 2 0}$ & $\mathbf{2 0 - 3 0}$ & $>\mathbf{3 0}$ \\
\hline $\begin{array}{c}\text { Respondent } \\
\text { pharmacists }\end{array}$ & $48.4(\%)$ & $22.6(\%)$ & $5.4(\%)$ & $23.6(\%)$ \\
\hline
\end{tabular}

The activity of dispensing medication containing opioid analgesics is being conducted in $71 \%$ of the questioned pharmacies (Fig. 2), of which 94.4\% (67 pharmacies) are located in the urban area, and only $5.6 \%$ (4 pharmacies) are located in a rural area.

The analysis of the collected data showed that $26 \%$ of the pharmacies which carry out activities of dispensing opioid analgesics are located near a hospital. This result emphasizes the fact that most of the patients have to rely on the pharmacy nearest to their home, which in $74 \%$ of the cases is not a hospital pharmacy.
Further investigation has focused on the proportion of opioid analgezics prescribed out of the total amount of medication dispensed and compensated by the national health insurance system in the respondent pharmacy.

For the majority of the questioned pharmacies (78.9\%), opioid analgezics account for less than $5 \%$ of the prescriptions that have been processed; in terms of financial value, for $70.1 \%$ of the pharmacies, this type of medicines represent less than $5 \%$ of total medicines compensated by the national health insurance and dispensed in the pharmacy (Fig. 3).

For $5.6 \%$ of pharmacies, this type of medication represents $10 \%$ of the total number of prescriptions processed; in terms of value, opioid analgesics represent $10 \%$ of the value of medicines compensated by the national health insurance system in $9.8 \%$ of pharmacies; these high values are found in pharmacies near oncology hospitals.

Considering the fact that not all the pharmacies have the activity of dispensing opioid analgesics, one of the main objectives of the study was to identify certain difficult situations that pharmacists encounter during the process. $37 \%$ of the pharmacists that have responded to this questionnaire assessed a very low demand in this type of medication from patients; this result can be motivated by the fact that in Romania

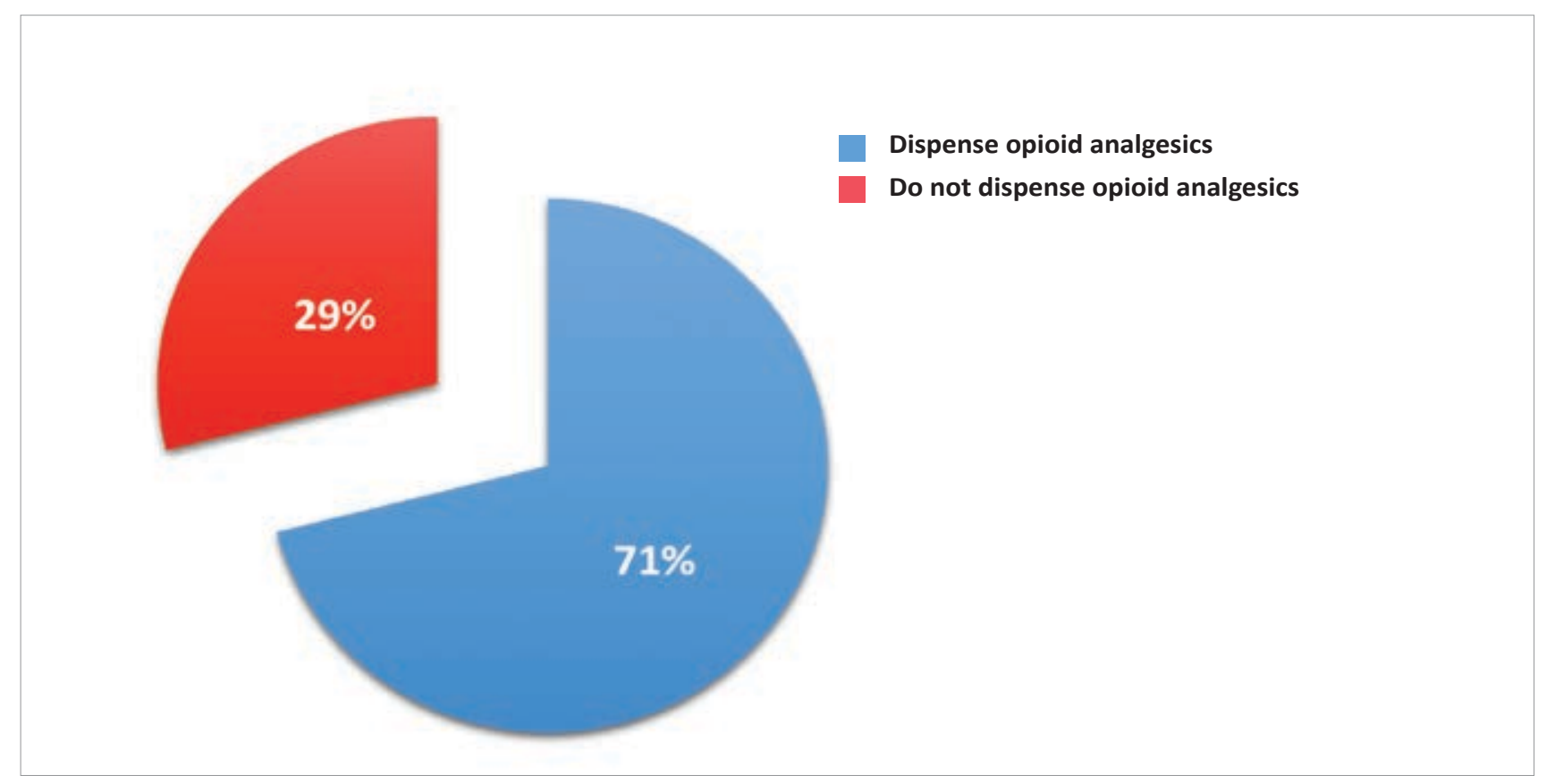

FIGURE 2. The graphic representation of the number of pharmacies that carry out the activity of dispensing opioid analgesic medication 


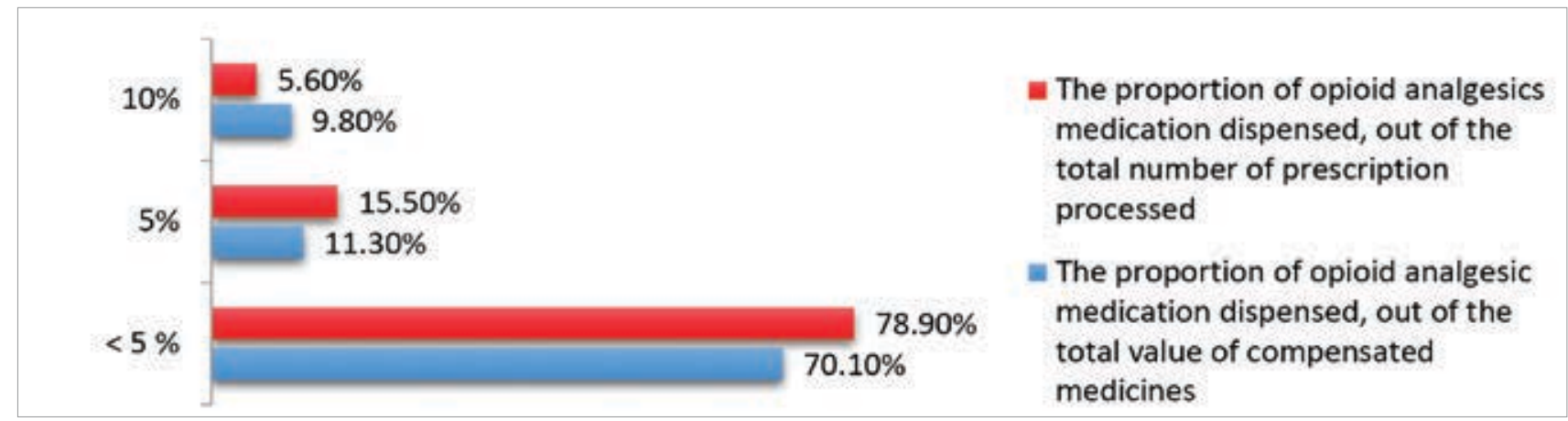

FIGURE 3. The proportion of opioid analgesics dispensed out of the total number of prescriptions dispensed, respectively out of the total value of compensated dispensed medicines

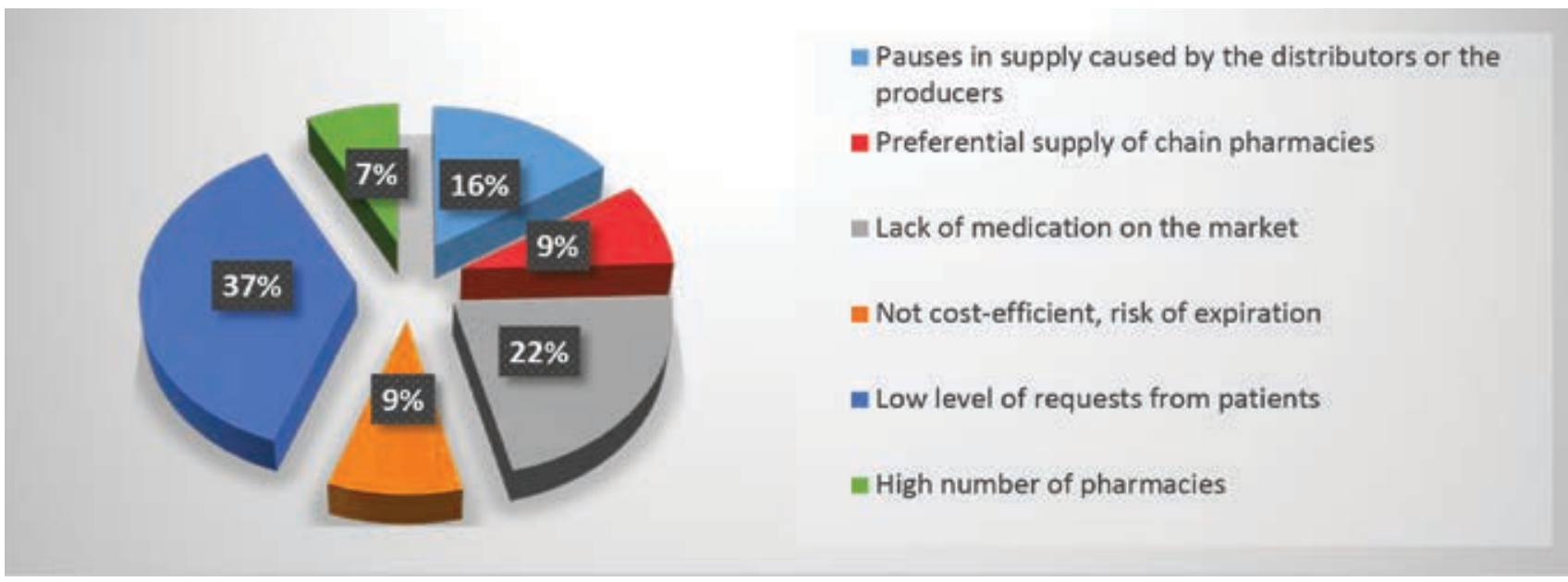

FIGURE 4. Problems encountered by the pharmacists during the activity of dispensing medication containing opioid analgesics

there is a sizeable number of pharmacies, most of them in the central-urban areas, without any geographical criteria being considered, which was mentioned by $7 \%$ of the respondents. Therefore, patients have to randomly address one of the pharmacies in the central area without developing a connection with the pharmacist or a preference for a specific pharmacy. On the other side, the vast majority of the central-urban pharmacies are part of a pharmacy chain or conglomerate which own the drug suppliers as well; as a consequence, these suppliers can preferentially supply their own pharmacies (mentioned by $9 \%$ of the respondents).

This problem becomes more evident when some of these drugs are missing from distributors' stocks. If the doctor prescribes and the pharmacist cannot dispense (16\% of the answers), patients from disadvantaged areas have to take another trip to the doctor to get a new prescription and if the medication cannot be substituted, the patients might be forced to interrupt treatment, which can have serious consequences. 9\% of the respondents have addressed the fact that dispensing opioid analgesics consumes too much time compared to the revenue that it generates and the risk of expiration is too high in the areas where there is a high density of pharmacies (Fig. 4).

The pharmaceutical forms that contain opioid analgesics have been analyzed, and the results are stated in therapeutical units. $14 \%$ of the questioned pharmacies dispense only solid forms (tablets), 19\% dispense solid forms in a proportion of $75 \%$ and in $30 \%$ of the pharmacies the tablets represent $50 \%$ of the total opioid analgesic medication.

Injectable products containing opioid analgesics account for $40 \%$, while transdermic systems for $38 \%$, in $25 \%$ of the questioned pharmacies (Fig. 5). The small number of transdermic systems prescribed is outlined by its therapeutic advantages, being administered less frequently than the other two pharmaceutical forms discussed (12).

The specific nature of this activity, which alongside with preparation and counselling implies as well 


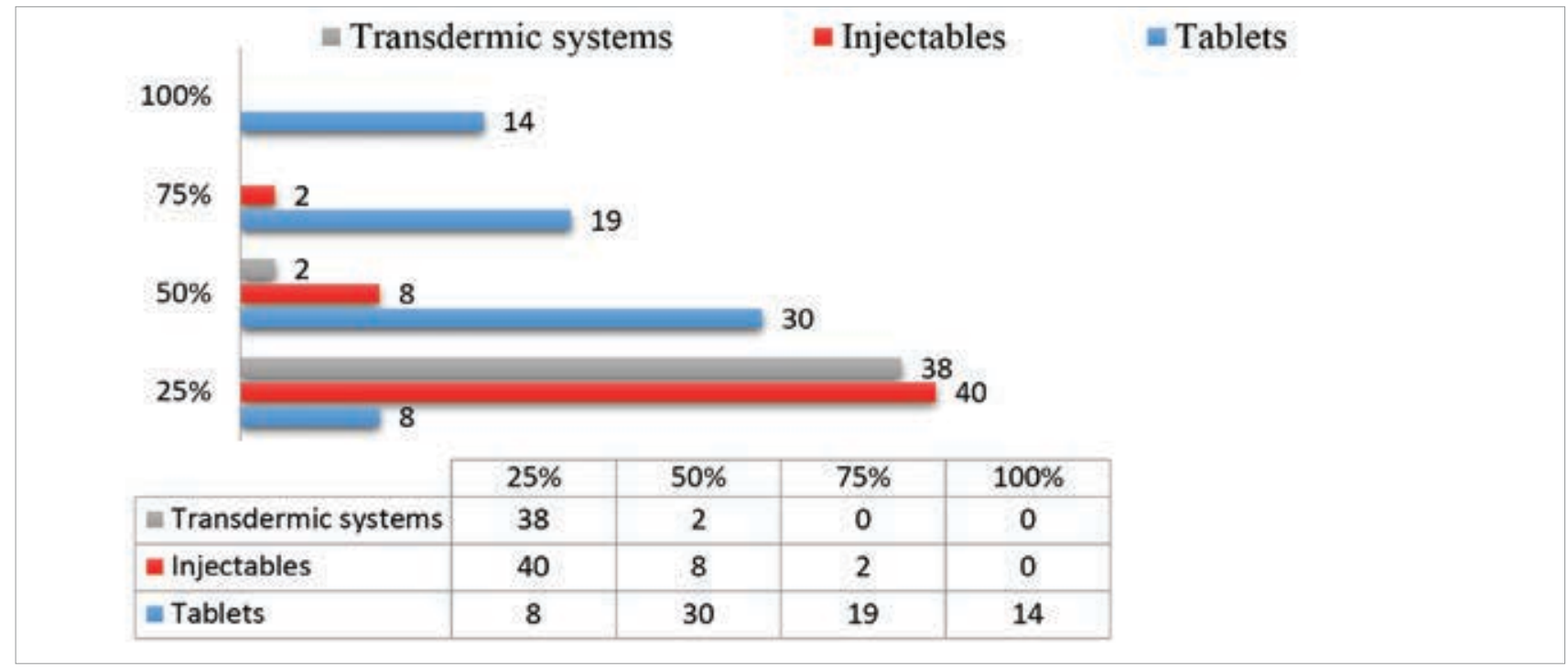

FIGURE 5. Distribution based on the pharmaceutical form (stated in therapeutical units) of dispensed opioid analgesic medication from the questioned pharmacies

recording of the evidence regarding opioid prescription processing, must be taken into consideration. In order to value the consumed resources necessary to process a prescription, the average time spent for a prescription was evaluated, considering every step that is implied (analysis of the prescription, preparation of the medicine, patient counselling, recording activity of the prescription).

The average time necessary to process a prescription with opioid analgesic drugs (only one drug per prescription) was estimated at $17.82 \pm 0.58$ minutes, most of the time being allocated for patient counselling (Fig. 6).

\section{CONCLUSIONS}

This paper evaluated the activity of dispensing opioid analgesic medication in 100 pharmacies from Romania, of which 96 are community pharmacies, the vast majority located in the urban area. The majority of pharmaceutical forms prescribed and dispensed, stated in therapeutical units, are the solid forms;

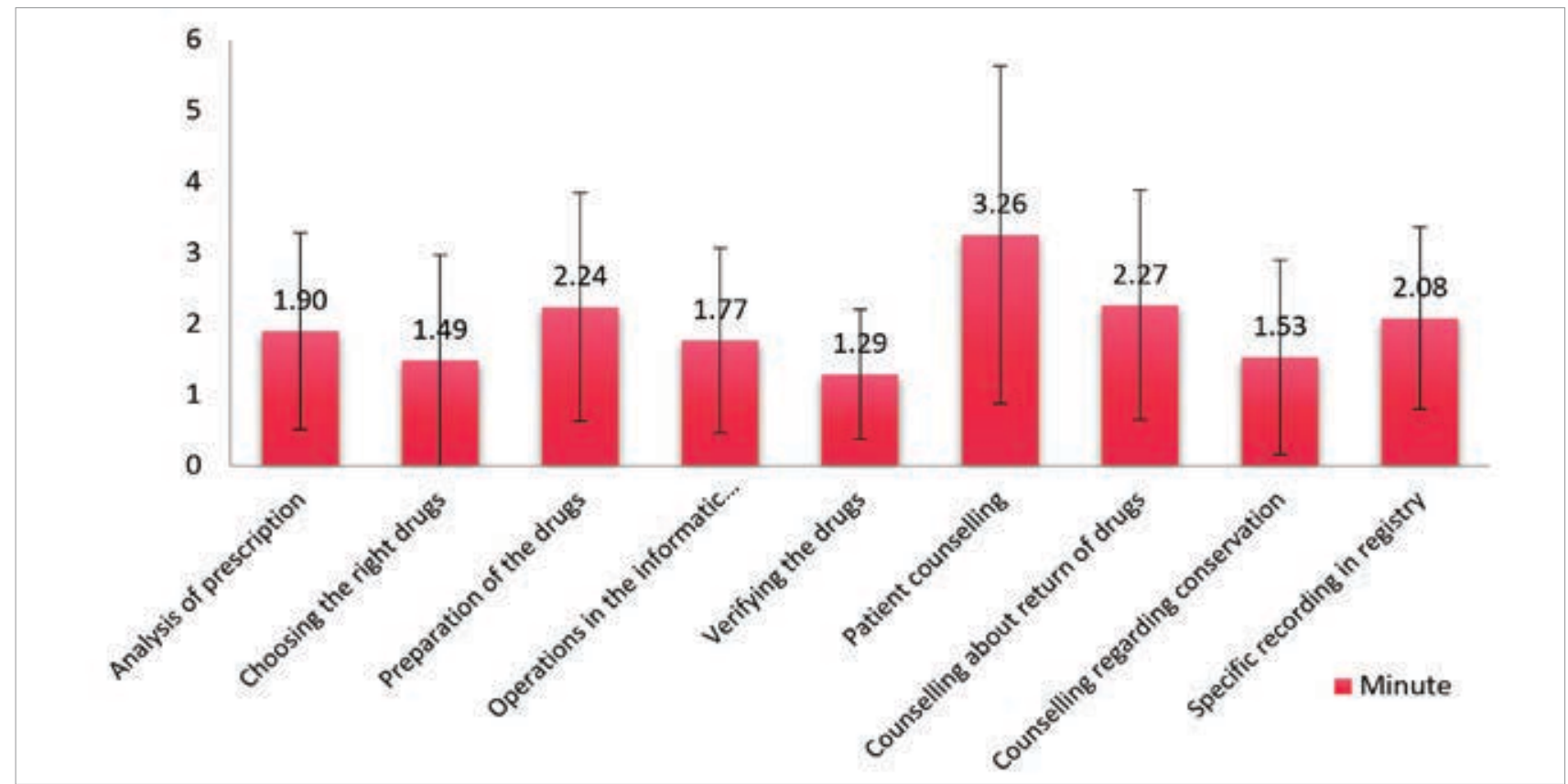

FIGURE 6. The average time necessary to process a prescription containing an opioid analgesic drug 
injectable forms and transdermic systems are dispensed $38 \%$ and $40 \%$ respectively in only $25 \%$ of the questioned pharmacies.

The problems which have been identified can affect the activity of dispensing opioid analgesic medication; the most notable are the low level of demand from patients (caused by the high number of urban pharmacies) and the difficulties regarding the supply. Moreover, the additional activities imposed for the manipulation of these drugs, the low cost-efficiency and the high risk of expiration dissuade independent pharmacies from performing this service to the patients. The average time necessary to process a prescription is $17.82 \pm 0.58$ minute, which furthermore reveal the high cost of time.

Conflict of interest: none declared Financial support: none declared

\section{REFERENCES}

1. Portenoy RK, Ahmed E. Principles of opioid use in cancer pain. Journal of Clinical Oncology. 2014;32(16):1662-1670.

2. Kim HJ, Kim YS, Park SH. Opioid rotation versus combination for cancer patients with chronic uncontrolled pain: a randomized study. BMC Palliat Care. 2015;14:41.

3. Tawfik MO, Bryuzgin V, Kourteva G. Use of transdermal fentanyl without prior opioid stabilization in patients with cancer pain. Curr Med Res Opin. 2004;20(3):259-67.

4. Marinangeli F, Ciccozzi A, Leonardis M, Aloisio L, Mazzei A, Paladini A, et al. Use of strong opioids in advanced cancer pain: a randomized trial. J Pain Symptom Manage. 2004;27(5):409-16.

5. Pârvu AE, Bulboacă A. Pathophysiology of pain. Volume of the symposium "The role of the pharmacist in pain therapy". Zaharia V (ed.). "Iuliu Haţieganu" University Medical Publishing House, Cluj-Napoca, 2010:1-17.

6. Cristea AN. Pharmacology, 1st Edition. Bucharest Medical Publishing House 2009;157-187.

7. Moşoiu D. Prescribing and using opioids in cancer pain management, practical guide for students, Lux Libris Publishing House Braşov, 2007:17.
8. Caraceni A, Hanks G, Kaasa S, Bennet MI, Brunelli C, Chernz N, Dale $\mathrm{O}$, et al. Use of opioid analgesics in the treatment of cancer pain: evidence-based recommendations from the EAPC. Lancet Oncol. 2012;13:e58-68.

9. Law no. 339/2005 on the legal frame of narcotic and psychotropic plants, substances and preparations, Official Gazette part I no. 1095/2005.

10. Law no. $143 / 2000$ on preventing and combating illicit drug trafficking and consumption, Official Gazette part I no. $362 / 2000$, amended and supplemented by Law no. 522/2004, Official Gazette part I no. 1155/2004.

11. Romanian Government Decision no. 1915/2006 for the approval of the Methodological Rules for the application of the provisions of Law no. 339/2005 regarding the legal frame of narcotic and psychotropic plants, substances and preparations, Official Gazette part I no. 18/2007.

12. Gordon DB. New opioid formulations and delivery systems, Pain Management Nursing. 2007;8(3):S6-S13. 